\title{
Investigation into the Self-loosening Trend of Bolt Joints on the Tower Crane
}

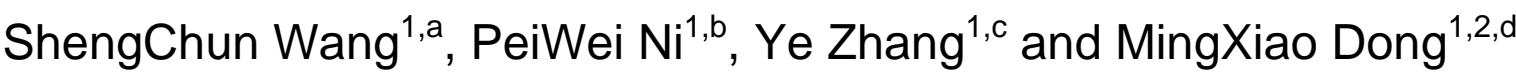 \\ ${ }^{1}$ School of Mechanical and Electrical Engineering, Shandong Jianzhu University, Jinan, \\ 250000, China \\ ${ }^{1}$ School of Mechanical Engineering, Shandong University, Jinan, 250000, China \\ aemail: scwang_0807@163.com, bemail:nipeiwei1990@163.com \\ cemail: 997484084@qq.com, demail: dongmingxiao @163.com
}

\begin{abstract}
Keywords: Self-loosening of Bolt Joints, Yamamoto's Method, Friction Coefficient, Vibrational Frequency, Transverse Amplitude of Vibration
\end{abstract}

\begin{abstract}
In this paper, a three-dimensional finite element model is developed based on the joints on standard sections of tower crane QTZ5510. The validity of this finite element model is verified through the contrast of analytical results calculated by Yamamoto Method and simulated ones under the action of static pre-tightening force. Dynamic analysis is carried out for investigating the impacts of coefficients, including friction coefficients of thread interfaces and pressured surfaces of bolt joints, vibrational frequencies and amplitudes of external displacement on the self-loosening of bolt joints. It is of great significance for the safety and reliability of tower cranes.
\end{abstract}

\section{Introduction}

Tower crane is a kind of high risk and accident rate equipment. As the support part of a crane, tower is composed of multiple standard sections, which are connected and fixed by bolt joints. Due to the varied working conditions the tower crane faced with, its structure is susceptible to different frequencies and mode shapes of vibrations. At the same time, bolt joints between the standard sections also suffer from lateral forces with different frequencies and amplitudes. However, on the long run, the vibration will lead to self-loosening of bolt joints, which decreases the stiffness of tower crane structure and separates standard sections, causing damages to the tower crane structure and even worse consequences. Researches of self-loosening of bolt joints between standard sections of tower crane are of great significance for the safety of the tower crane, both design and usage.

The self-loosening of bolt joint refers to phenomenon about the loss of clamping force under the action of vibration on fasteners. This phenomenon is particular distinct when the vibrational displacement is lateral. Plenty of studies have been made about the mechanism of self-loosening of bolt joints. Junker[1] studied the self-loosening behavior of threaded fasteners subjected to cyclic lateral excitation, and came to a conclusion that the loosening process is more severe when the joint is under the action of dynamic transverse loads (shear loads). Haviland[2] stated that the ratcheting action of nuts resulted in the loosening, providing no mathematical model or experimental data to support his theory. Yamamoto and Kasei[3] investigated another mechanism for the self-loosening of bolts subjected to cyclic transverse loads. They concluded that the loosening happens due to the accumulation and release of potential energy of the torsional deformation of bolts. Nassar and Housari[4-7] introduced a mathematical model and an experimental procedure to study the threaded fastener loosening phenomena under cyclic transverse loads. They investigated the effect of thread pitch, pre-tightening force, clearance thread fit, thread friction, and amplitude of the cyclic transverse load on the loosening of bolt. They concluded that both of these parameters have a significant effect on the occurrence of self-loosening. G. Dinger and C. Friedrich[8] studied details of the rotational self-loosening process by a three-dimensional finite element model, and concluded that self-loosening occurs when local slipping happens without complete slipping at the head contact surface. 
This paper associates simulations of finite element analysis with actual conditions, and establishes the finite element model of bolt joints on the standard sections of tower crane QTZ5510 by combinational usage of finite element software. The reliability of the finite element is proved by a numeric compare between an analytical method and the simulated way. After that, the paper mainly studies the influence of friction coefficients of thread interfaces and pressured surfaces, frequencies and the amplitudes of lateral vibration on self-loosening of bolt joints, in combination with the conclusions Shengchun Wang[9] drawn from the modal analysis of tower crane.

\section{Establishment of Three Dimensional Finite Element Model}

In this paper, a three-dimensional geometry model of bolt joints on standard sections of tower crane is established, and a meshed model is also created by a finite element preprocessor software. On standard sections of tower crane QTZ5510, high strength hex bolts and nuts are generally used in bolt joints. The specification of the thread is M33 $\times 2$. Firstly, proper simplifications have been made before the establishment of the geometry model, such as deletions of all gaskets, shortening nut thread for simplifying calculation and improving mesh quality, and substituting hexagon areas for circular ones. The establishing and assembling processes are finished before the geometry model is imported in the finite element preprocessor software for pretreatment of finite element analysis. The pretreatment includes definition of material properties, meshing, establishment of contact areas together with setting up contact pairs and corresponding properties. Finally, the model is imported into a finite element analysis software for setting up load steps and boundary conditions, exerting pre-tightening force and external vibrations before the final operation. The three-dimensional finite element model of the bolt joint is shown in Figure1.

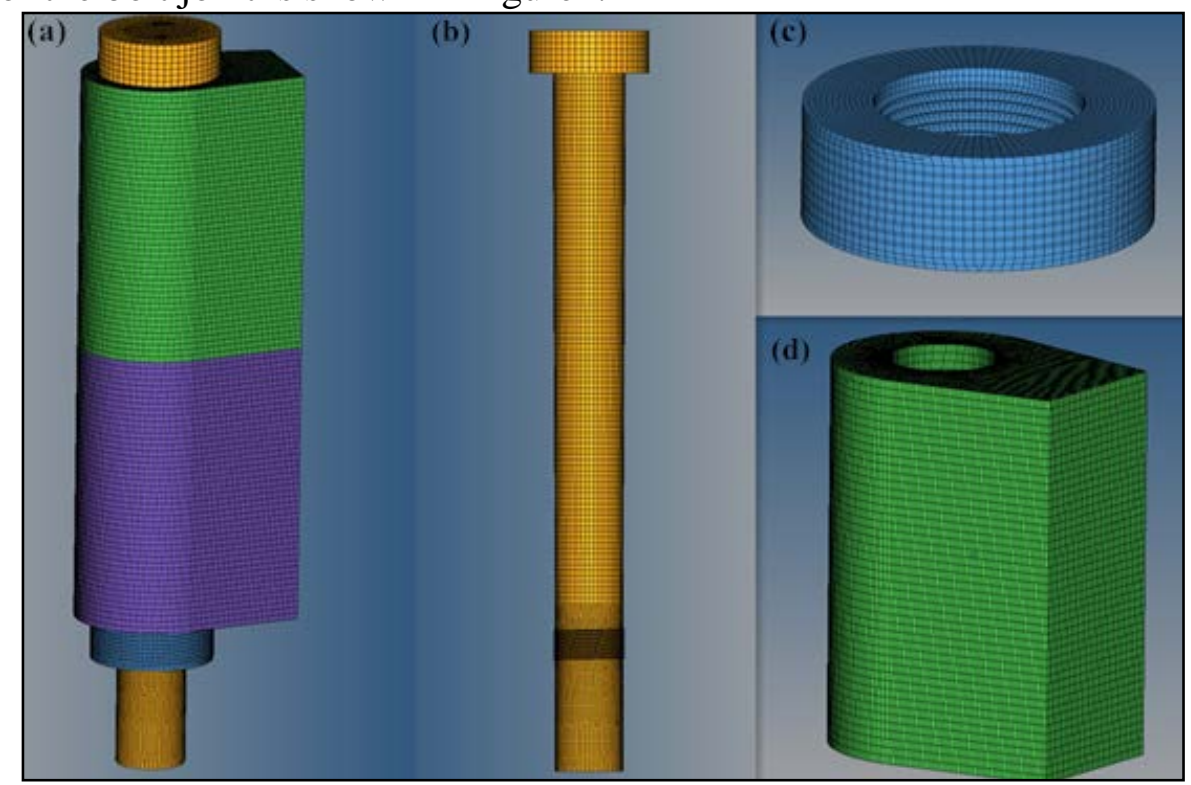

Fig.1. Three-dimensional finite element model of (a), (b) bolt, (c) nut and (d) fastener The materials and corresponding properties of bolt, nut and fasteners are shown in Table 1.

Tab.1. Materials and corresponding properties of the bolt, the nut and fasteners

\begin{tabular}{ccccc}
\hline Parts & Material grades & $\begin{array}{c}\text { Elastic } \\
\text { modulus } \times \\
10^{11} /\left(\mathrm{N} \cdot \mathrm{m}^{-2}\right)\end{array}$ & Poisson ratio & $\begin{array}{c}\text { Density } \times \\
10^{3} /\left(\mathrm{kg} \cdot \mathrm{m}^{-3}\right)\end{array}$ \\
\hline Bolt & 5140 & 2.09 & 0.295 & 7.85 \\
Fasteners & 1045 & 2.10 & 0.269 & 7.89 \\
Nut & 5140 & 2.09 & 0.295 & 7.85 \\
\hline
\end{tabular}

\section{Analytical Method of the Distribution of Bearing Capacity of Threads}

In this paper, the simulated distribution of bearing capacity of threads under the action of static 
pre-tightening force is compared with the analytical one from Yamamoto's method[10], to validate the accuracy of this finite element model.

Yamamoto's method is a way for calculating the distribution of bearing capability of threads. It divides the deformations of threads into four categories on the premise of ignoring helix Angle and regarding the thread as plane strain beams. The four categories include bend and shear deformation, incline distortion on thread roots, deformations caused by shear force exerted on thread roots and radial shrinkage deformation of the bolt and nut. On this basis, the method deduces the distribution of thread stress layer by layer according to the deformation compatibility condition of bolts, nuts and their threads. As a kind of analytical method that could reflect the distribution of load stress on the threads, Yamamoto's method is widely accepted by researchers.

According to the theory of Yamamoto[10], $\delta_{1}, \delta_{2}$ refer to bend and shear deformations, $\delta_{3}$ means the incline distortion on thread roots, $\delta_{4}$ is the deformation caused by shear forces exerted on thread roots, $\delta_{5}$ represents radial shrinkage deformations of bolt and nut. $\alpha$ is flank Angle of the thread, $\omega$ are pressures exerted on thread surfaces along the normal direction.

Deformations of bolt and nut are shown below.

$$
\begin{aligned}
& \delta_{\mathrm{n}}=\delta_{1 \mathrm{n}}+\delta_{2 \mathrm{n}}+\delta_{3 \mathrm{n}}+\delta_{4 \mathrm{n}}+\delta_{5 \mathrm{n}}=\frac{\mathrm{k}_{\mathrm{n}}}{\mathrm{E}_{\mathrm{n}}} \mathrm{w} \cos \alpha \\
& \delta_{\mathrm{b}}=\delta_{1 \mathrm{~b}}+\delta_{2 \mathrm{~b}}+\delta_{3 \mathrm{~b}}+\delta_{4 \mathrm{~b}}+\delta_{5 \mathrm{~b}}=\frac{\mathrm{k}_{\mathrm{b}}}{\mathrm{E}_{\mathrm{b}}} \mathrm{w} \cos \alpha
\end{aligned}
$$

In (1), (2), $\mathrm{k}_{\mathrm{n}}, \mathrm{k}_{\mathrm{b}}$ are comprehensive coefficient of elastic deformation of internal and external threads. $\mathrm{D}_{0}$ is the diameter of the circle that has equivalent square with hexagonal areas of bolt and nut. $d_{p}$ represents the effective diameter of external threads. The values of $k_{b}, k_{n}$ are shown below:

$$
\mathrm{k}_{\mathrm{b}}=6.184, \quad \mathrm{k}_{\mathrm{n}}=8.142
$$

The distribution of thread stress can be obtained from the following equations:

$$
\begin{aligned}
& \lambda=\sqrt{\frac{\frac{1}{\mathrm{~A}_{\mathrm{b}} \mathrm{E}_{\mathrm{b}}}+\frac{1}{\mathrm{~A}_{\mathrm{n}} \mathrm{E}_{\mathrm{n}}}}{\left(\frac{\mathrm{k}_{\mathrm{b}}}{\mathrm{E}_{\mathrm{b}}}+\frac{\mathrm{k}_{\mathrm{n}}}{\mathrm{E}_{\mathrm{n}}}\right) \tan \beta}} \\
& \frac{\mathrm{F}}{\mathrm{F}_{\mathrm{n}}}=\frac{\sinh \lambda \mathrm{x}}{\sinh \lambda \mathrm{L}}
\end{aligned}
$$

Among them, $F_{n}$ represents the axial force exerted on the bolt, $\beta$ is the thread angle, $L$ is the thickness of the nut. From (5), the distribution of axial force F on contact sections of bolt thread can be obtained. Analytical results of the axial forces and coefficients of bolt threads are shown in Tab.2.

Tab.2. Analytical results of the axial forces and coefficients of bolt threads

\begin{tabular}{ccc}
\hline $\begin{array}{l}\text { Number of } \\
\text { thread }\end{array}$ & $\begin{array}{l}\text { Axial force } \\
\mathrm{F}_{\mathrm{a}}(\mathrm{N})\end{array}$ & $\begin{array}{l}\text { Coefficient } \\
\text { of axial } \\
\text { force } \\
\mathrm{F}_{\mathrm{a}} / \mathrm{F}_{\mathrm{n}}\end{array}$ \\
\hline 1 & & 0.0674 \\
2 & 91.67 & 0.1365 \\
3 & 185.64 & 0.21 \\
4 & 285.6 & 0.2872 \\
5 & 390.592 & 0.3727 \\
6 & 506.872 & 0.4679 \\
7 & 636.344 & 0.575 \\
8 & 782 & 0.6975 \\
9 & 948.6 & 0.8379 \\
10 & 1136.544 & 1 \\
\hline
\end{tabular}




\section{Simulation of Finite Element Model of the Bolt Joint}

Boundary conditions are set up on the fastener contacting the bolt head whose six degrees of freedom are restrained. At the same time, the bolt and nut are kept in free condition for a more realistic simulating condition. After the pre-tightening force is applied, the stress distribution of thread contacting sections is shown in Figure 2.

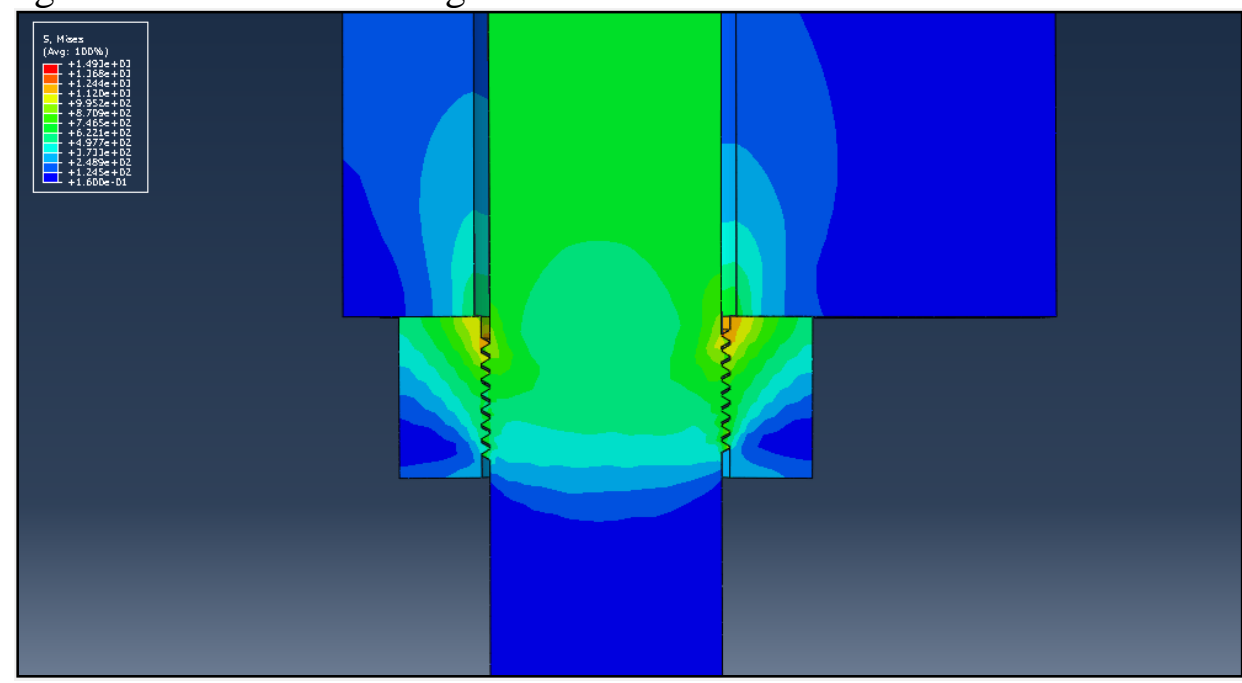

Fig.2. The stress distribution of thread contacting sections

Axial forces that represent contact stresses of contact threads are used to compare with the results calculated by analytical method. The simulated results of axial forces and axial force coefficients of contact threads are shown in Table 3.

Tab.3. Simulated results of axial forces and axial force coefficients of contact thread

\begin{tabular}{ccc}
\hline $\begin{array}{l}\text { Number } \\
\text { Thread }\end{array}$ & $\begin{array}{l}\text { Axial force } \\
\mathrm{F}_{\mathrm{a}}(\mathrm{N})\end{array}$ & $\begin{array}{l}\text { Coefficient } \\
\text { of } \\
\text { force } \mathrm{F}_{\mathrm{a}} / \mathrm{F}_{\mathrm{n}}\end{array}$ \\
\hline 2 & 432.008 & 0.3177 \\
3 & 507.571 & 0.3732 \\
4 & 569.358 & 0.4186 \\
5 & 617.909 & 0.4543 \\
6 & 652.608 & 0.4799 \\
7 & 754.289 & 0.555 \\
8 & 950.708 & 0.6991 \\
9 & 1115.6 & 0.8203 \\
\hline
\end{tabular}

\section{Comparison and Verification}

According to analytical results calculated by Yamamoto's method and simulated results of the finite element analysis, distribution curves of bearing capacity of bolt threads are drawn in Figure 3. 


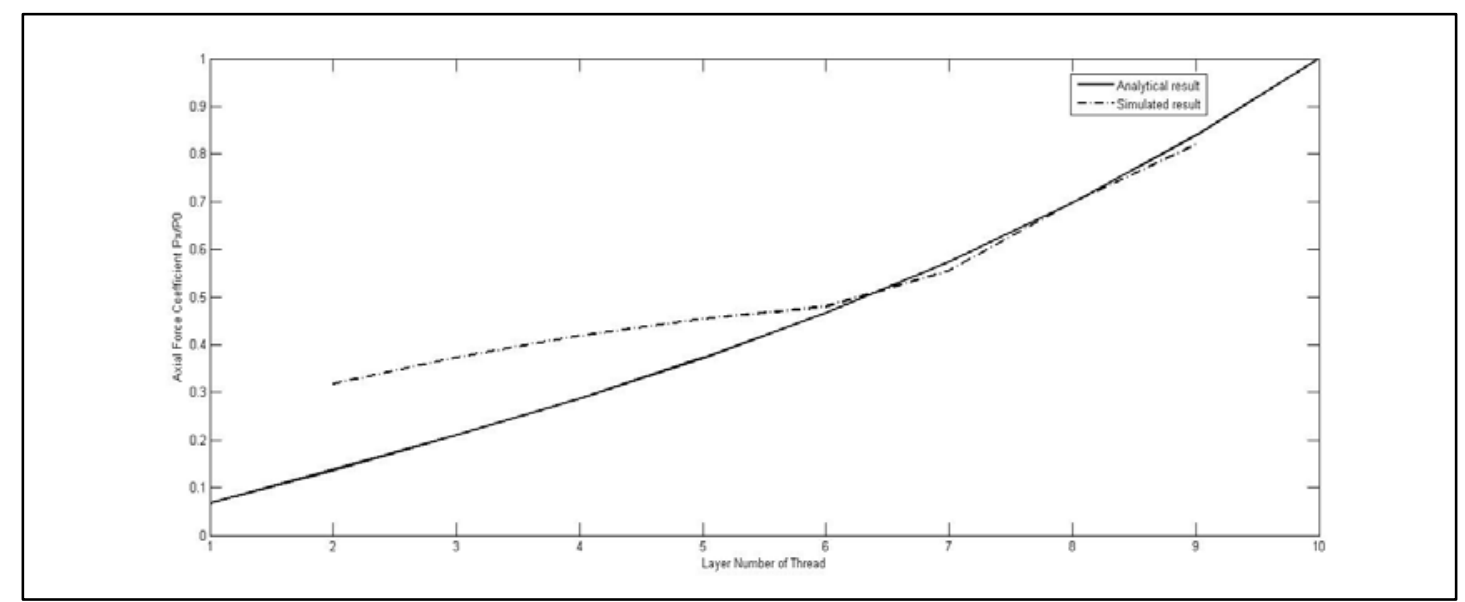

Fig.3. Bearing capacity distributions of results and simulated results

From Figure 3, it is distinct that the simulated results coincide with the analytical results near the contacting surfaces of nut and fastener, but deviation appears between the two curves closing to the free surface of the nut. Because Yamamoto's method ignores the helix Angle, the whole thread is separated into multiple circles. Therefore, the circles near the free surface of the nut are only acted upon by axial force from the corresponding circles of the bolt. However the simulation model is established with helix angle which has an intact curve of thread, the force status of the lower thread is also influenced by the stress and deformation of the upper thread. So the deviation between the two curves close to the free surface of the nut is understandable. In a word, the simulation of the three-dimensional finite element model in reflecting the stress status of the bolt joint is acceptable.

\section{Investigation of self-loosening mechanism of bolt joint}

An external excitation is necessary for the finite element analysis of bolt joints on standard sections of the tower crane. After exerting pre-tightening force and setting up the boundary conditions, a lateral excitation is exerted on the lower fastener along $\mathrm{z}$ axis. The calculating formula for $\mathrm{z}$ is as followed:

$$
\mathrm{z}=\mathrm{z}_{0} \sin (\omega \mathrm{t})
$$

Where $\mathrm{z}_{0}, \omega$ are the amplitude and the angular frequency.

The friction factors of the contact surfaces are also set. $\mu$ is the friction factors of thread contact surface, $\mu_{1}$ is that of contact surfaces on bolt head and fastener, $\mu_{2}$ is that of contact surface on nut and fastener, $\mu_{3}$ is that of contact surfaces on two fasteners. In addition, the value of the pre-tightening force exerted in this model is $1360 \mathrm{~N}$.

This paper focuses on the influence of the vibration frequency, the coefficient of thread mating surface and pressured surface, and the amplitude of lateral displacement on self-loosening of bolt joints, and investigates the distribution of bearing capacity of the bolt thread and rules of its stress variation under the effect of external vibration. According to the three natural frequencies of tower crane QTZ5510 measured by Shengchun Wang[9], the simulation results are closer to the actual situation.

\section{Analysis of Bolt Loosening Trend}

In order to understand the impact of dynamic displacement to the variation of stress of the contact thread, three elements, separated by 90 degrees, are selected to study the stress condition in the moving process of fasteners. It studies the stress condition of the nut thread under external excitation of displacement exerted every $1 / 4$ cycle in 4 cycles time. Each cycle lasts $0.64 \mathrm{~s}$. The friction coefficients are all 0.1 , and the magnitude of displacement is $0.25 \mathrm{~mm}$. The selected elements are shown in Figure 4. 


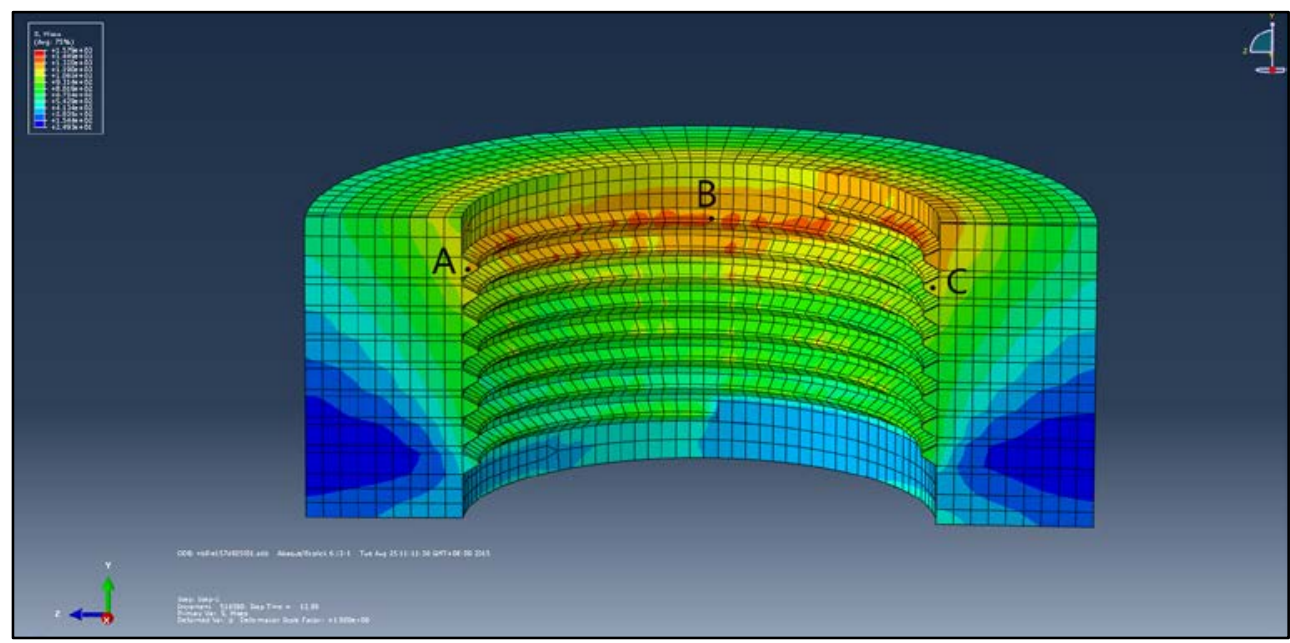

Fig.4. Positions of element A, B and $\mathrm{C}$ on the nut

The fastener moves along the negative direction of $\mathrm{z}$ axis under the periodic action of vibrational displacement, which initiates from the original time. From Figureue.4, it can be seen that the distance between element $\mathrm{A}$ and the contact surface of the nut is the nearest, that of element $\mathrm{B}$ comes the second and element $\mathrm{C}$ is the farthest.

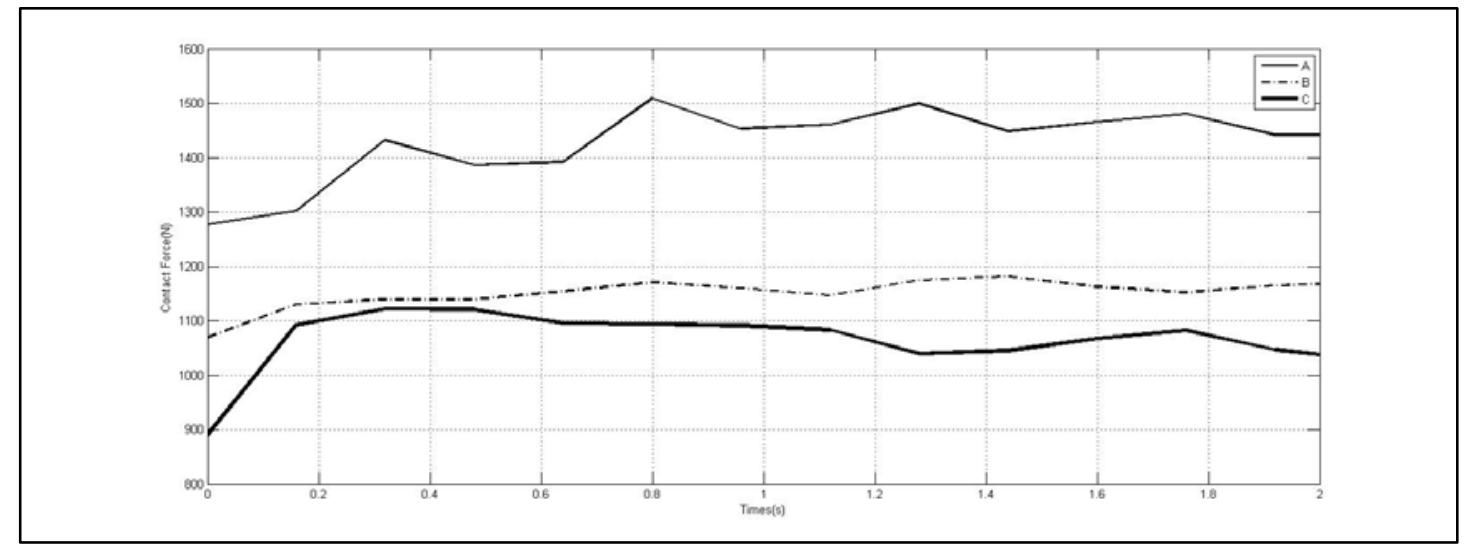

Fig.5. Stress conditions of element A, B and C

According to Figure 3, the stress element A suffered is the largest, the stress of B comes the second and the stress of $\mathrm{C}$ is the smallest. It is supported by the conclusion drawn from Figure5. The accuracy of the model is proved again. In addition, as can be seen from the Figure 6, when the curve of excitation is rising, the fastener moves along the positive direction of $\mathrm{z}$ axis, the deformation around $\mathrm{C}$ is larger than that of $\mathrm{A}$. The stress is in a state of increscent and the stress changes intensely at the same time. However, the stress state of A is reduced, and the stress changes smoothly. When the curve of excitation declines, the fastener moves along the negative direction of $\mathrm{Z}$ axis, the thread around $\mathrm{A}$ is squeezed, the stress begins to increase at this time. The stress of $\mathrm{C}$ decreases gradually, and the change is moderate than that of A. Due to the Minimum displacement and deformation occurred around $\mathrm{B}$, the change of curve $\mathrm{B}$ is gentle. However, the stress of A and C tends to decrease with the time elapsing. With the fastener keeps moving to and fro, the tendency leads to the decrease of residual pre-tightening force, which even causes local slips of contact threads resulting in self-loosening of bolt joint[11].

\section{Impact of Friction Coefficient of Thread Interface on the Self-loosening of Bolt Joints}

The normal work of the bolt joint refers to the stable condition bolts and nuts keep under the action of pre-tightening force, with the help of friction angles. When the movement of the fastener impacts the contact part of thread, the interface of threads is the primary spot of stressing and deforming. The stress and deformation are also key factors of self-loosening of bolt joints. In order to investigate the influence of friction coefficients of thread interfaces on bolt self-loosening, various values of $\mu$ are taken for comparative simulations while the values of $\mu_{1}, \mu_{2}$ and $\mu_{3}$ 
remain unchanged. The force curves composed by force conditions of the bolt thread under the condition of various friction coefficients of thread interfaces are shown in Figure6.

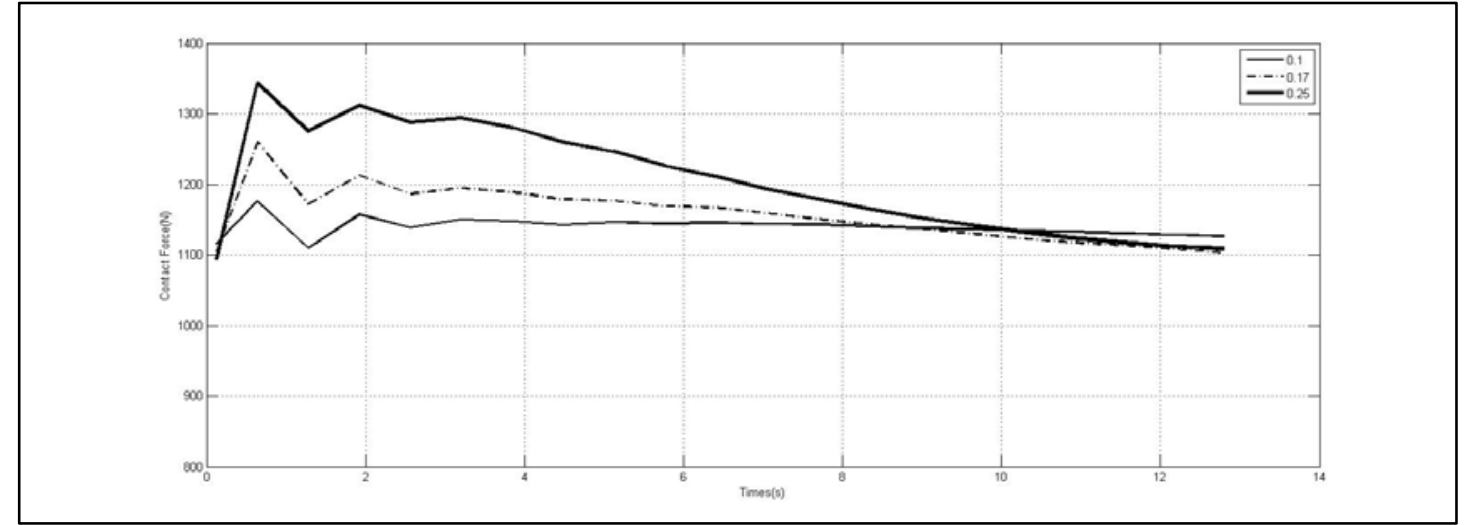

Fig.6. Force curves reflecting the impact of friction coefficients of thread interfaces

From Figure 6, the stress of contact threads tends to be leveling off after a period of fluctuation while the pre-tightening force changes from static state to dynamic. Simultaneously, the larger the friction coefficient is, the greater the loss of pre-tightening force is. After 20 cycles, all of these three curves tend to decreasing. With the same preload and other factors, greater friction coefficients result in higher self-loosening possibilities.

\section{Impact of Friction Coefficient of Pressured surfaces on the Self-loosening of Bolt Joints}

There are three kinds of pressured surfaces in this bolt joint: the pressured surface of bolt head, the pressured surface of nut and the pressured surface of fasteners. When the excited fastener moves, the movement is transferred to the bolt by frictions of pressured surfaces. The transferred movement rotates bolt head and becomes one of primary factors for self-loosening of bolt joints. To investigated the impact of friction coefficient of pressured surfaces on the self-loosening of bolt joints, various values of $\mu_{1}, \mu_{2}, \mu_{3}$ are taken for comparative simulations while the value of $\mu$ remains unchanged. The force curves composed by force conditions of the bolt thread under the condition of different friction coefficients of pressured surfaces are shown in Figure7.

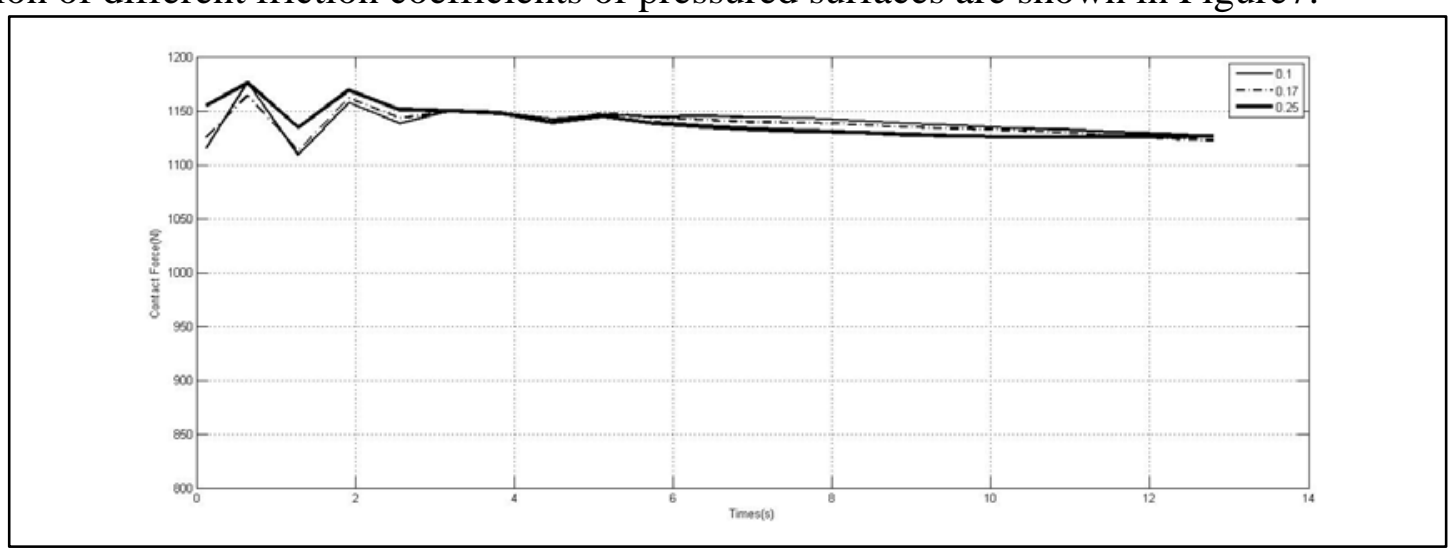

Fig.7. Force curves of different friction coefficients of pressured surfaces

As can be drawn from Figure 7, the bigger the coefficient, the greater the loss of preload. However, compared with the thread interface friction coefficient, the change of pressured surface friction coefficient is more inconspicuous. With invariant magnitude and frequency of lateral displacement, the thread interface friction coefficient has a small impact on self-loosening of bolt joint.

\section{Impact of vibration frequency on self-loosening of bolt joints}

$0.536 \mathrm{~Hz} 、 0.628 \mathrm{~Hz} 、 1.57 \mathrm{~Hz}$, three natural frequencies of tower crane QTZ5510, are simulated for investigating the impact of vibration frequency on bolt self-loosening in the case of steady friction 
coefficients and vibration amplitudes. Since cycle times vary from different frequencies, 20 cycles are used to simulate the frequencies of $0.536 \mathrm{~Hz}$ and $0.628 \mathrm{~Hz}$, and 40 cycles for $1.57 \mathrm{~Hz}$. The achieved curves of force condition of bolt thread are shown in Figure 8.

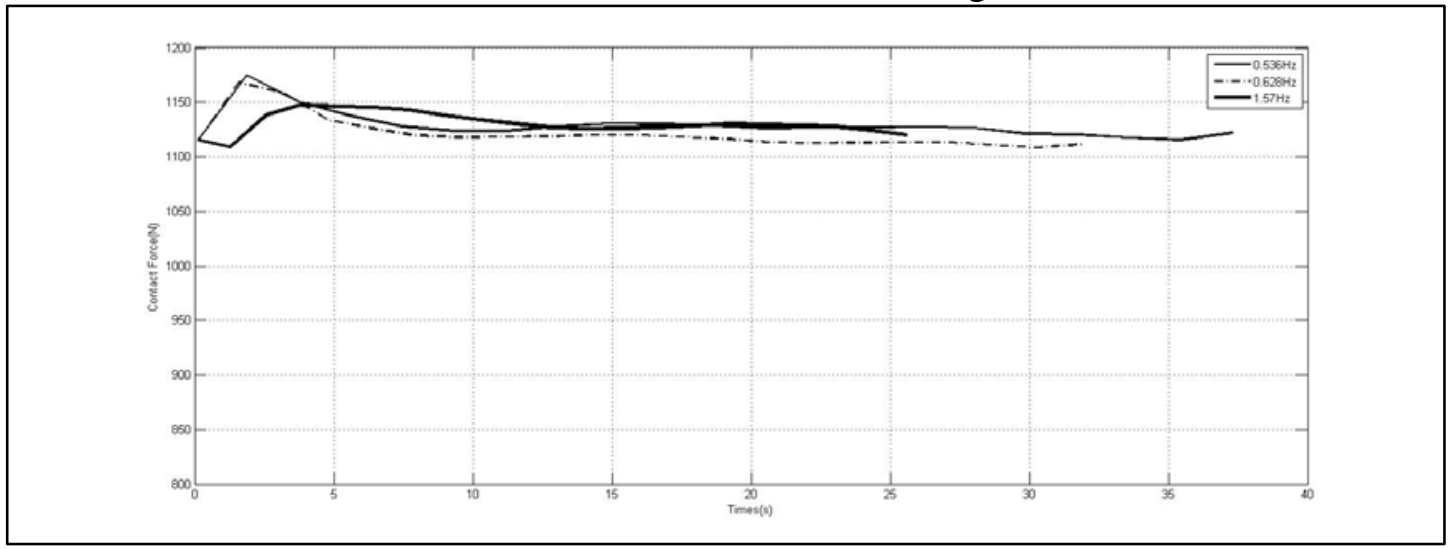

Fig.8. Force curves of different vibrational frequencies

$0.536 \mathrm{~Hz}$ reflects vibration frequency of the tower crane swinging around fixed points. $0.628 \mathrm{~Hz}$ refers to the vibration frequency when balance arms and booms bend in vertical plane. $1.57 \mathrm{~Hz}$ corresponds to vibration frequency of balance arms and boom bending in horizontal plane. From Figure 8, when the vibration frequency is $0.628 \mathrm{~Hz}$, the loss of residue preload reaches the maximum. It implies that the bending of balance arms and booms of tower crane impact the self-loosening of bolt joints on standard sections the most among three vibrational frequencies of tower crane structures.

\section{Impact of Amplitude of Transverse Vibration on the Self-loosening of Bolt Joint}

When a tower crane is in different working conditions or lifting objects with different weights, the swing amplitudes of the tower structure are diverse. Moreover, when a tower crane swings, the swing amplitude increases gradually from bottom to top, which results in diverse magnitudes of displacement between different standard sections. In order to study the impact of magnitudes of transverse vibrations on the self-loosening of bolt joints, various vibration magnitudes are simulated while friction coefficients and vibration frequencies are invariant. The curves of stress variation of the bolt thread are shown in Figure 9.

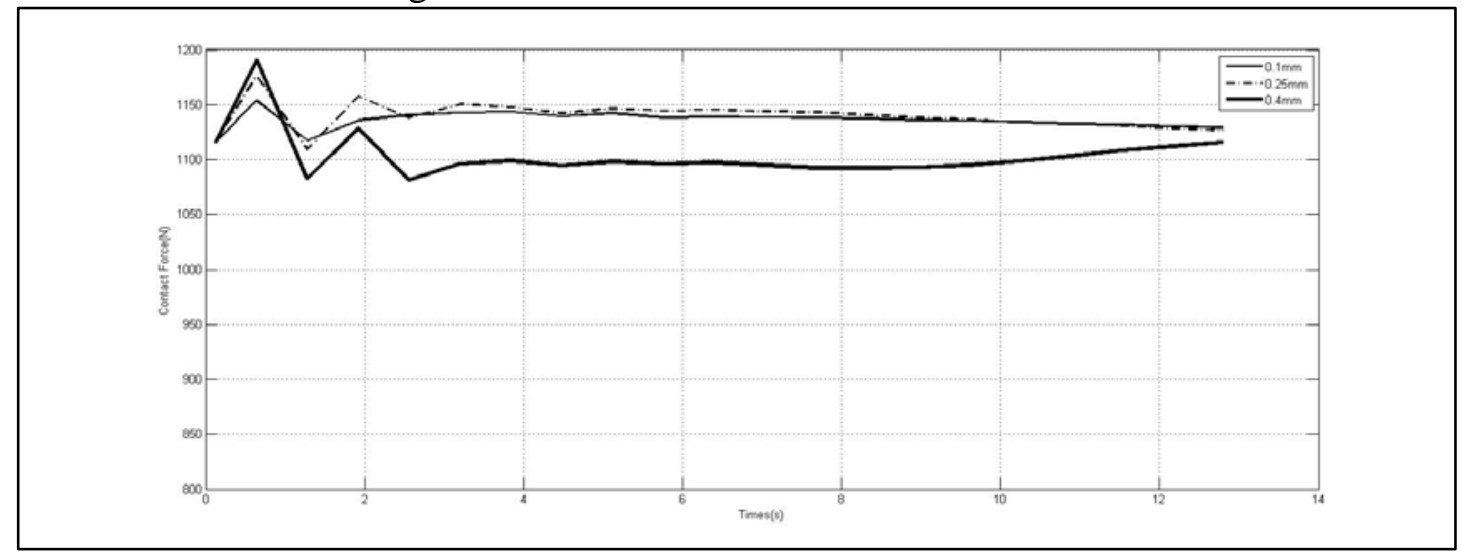

Fig.9. Force curves of varies amplitudes

From Figure 9, the larger the vibration amplitude is, the greater the residuary preload lost. It means that when tower crane swings, the bolt joint are likely to loose at the position where the greatest swing amplitude occurs.

\section{Conclusion}

In this paper, a finite element model of bolt joint on standard sections of tower crane QTZ5510 is established. The validity of this model is proved by the method of Yamamoto. By the dynamic 
analysis of the model under the action of lateral vibration, the following conclusions that focused on the impact of friction coefficient of the thread interfaces and pressured surfaces, vibration frequency and amplitude of the fastener on self-loosening of bolt joints can be reached.

The loss of residue preload increases as values of friction coefficient of thread interface rises, the relative slip is not easy to happen, which indicates that the smaller the friction coefficient of thread interface is, the less likely the self-loosening of bolt joints happens. When lateral vibrational frequency stays unchanged, the friction coefficients of pressured surfaces have little impact on self-loosening of bolt joints. By compares of vibrational frequencies under different working conditions of tower crane, the maximum displacement occurs when its balance arm and boom curve in vertical plane.

The dynamic analysis of this FEM lasts only 20 to 40 cycles due to the operation conditions, which makes the decrease of residue pre-tightening forces seems inconspicuous, but their declining trends are visible. The detailed self-loosening of bolt joints on tower cranes still need for further investigation.

\section{References}

[1] Junker GH. New Criteria for Self-Loosening of Fasteners Under Vibration. Sae Transactions. 1969; 78: 75.

[2] Haviland and G.S. Designing With Threaded Fasteners. Mechanical Engineering. 1983; 105: $17-31$.

[3] Yamamoto, A., Kasei. and S. A Solution for the Self-loosening Mechanism of Threaded Fasteners Under Transverse Vibration. Journal of the Japan Society of Precision Engineering. 1984; 18: 261-6.

[4] Nassar, A. S, Housari and A. B. Effect of Thread Pitch on the Self-Loosening of Threaded Fasteners Due to Cyclic Transverse Loads. ASME J Pressure Vessel Technol. 2006; 128: 590-8.

[5] Nassar SA and Housari BA. Study of the Effect of Hole Clearance and Thread Fit on the Self-Loosening of Threaded Fasteners. Journal of Mechanical Design. 2007; 129: 1053-62.

[6] Housari BA and Nassar SA. Effect of Thread and Bearing Friction Coefficients on the Vibration-Induced Loosening of Threaded Fasteners. Journal of Vibration \& Acoustics. 2007; 129: 484-94.

[7] Housari and A. B. Vibration-Induced Loosening of Threaded Fasteners. Ph.D. Thesis. Oakland University.Rochester.2007.

[8] Dinger G and Friedrich C. Avoiding self-loosening failure of bolted joints with numerical assessment of local contact state. Engineering Failure Analysis. 2011; 18: 2188-200.

[9] Wang S, Song S, Jin T and Wang J. Modal Analysis of a Tower Crane Structure. Mechanical Science and Technology for Aerospace Engineering. 2010; 29: 912-4.

[10] A. Y. The theory and computation of threads connection. Tokoy: Yokendo, 1980.

[11] Zhang M, Jiang Y and Lee CH. Finite Element Modeling of Self-Loosening of Bolted Joints. Journal of Mechanical Design. 2007; 129: 218-26. 